\title{
Management of Food Safety Risks in India
}

\author{
SIRUGURI VASANTHI ${ }^{1}$ and RAMESH V BHAT ${ }^{2, *}$ \\ ${ }^{1}$ National Institute of Nutrition, Hyderabad 500 007, India \\ ${ }^{2}$ M 11, Kakateeyanagar, Habshiguda, Hyderabad 500 007, India
}

(Received on 09 June 2018; Accepted on 20 June 2018)

\begin{abstract}
Food safety is of vital importance not only for human health but also from the perspective of economic costs. Various physical, biological and chemical agents are capable of making food unsafe for human and animal consumption. In the Indian context a variety of food toxicants, contaminants and adulterants have been found to be responsible for several food-borne disease outbreaks in humans and animals. The economic consequences of food toxicants and contaminants both in terms of health costs and reduced earnings are considerable. In the modern globalized era when food travels across continents, keeping the food safe and secure from contamination risk during the entire food chain is the shared responsibility of the producers, processors, traders and the Government. This paper discusses various aspects of food safety risk management in India including the institutional set up, standards and regulations. It evaluates the existing framework of food safety regulations and their management (including impact assessment) in terms of cost effectiveness, pointing out the current lacunae and making suggestions for building capacity to strengthen the system. The topic is discussed both from the national and international perspectives in the specific context of meeting the Sustainable Development Goals (SDGs).
\end{abstract}

Keywords: Food Safety Risk Management; Human Health; WHO; Global Population

\section{Introduction}

Safe and nutritious food is vital for sustaining life and promoting good health. Food safety hazards, both acute and chronic, constitute one of the major global public health concerns (WHO, 2016). Because food supply is now crossing international borders, the food safety problem in one country can become a global concern. According to a recent study, food-borne diseases are increasing at an alarming rate in India due to consumption of contaminated food (Kristkova et al., 2017). Improper post-harvest processing, inadequate storage and transport facilities, and insufficient knowledge and awareness of the hazards associated with poor quality food, increase the potential risk of consuming unsafe food (FAO, 2005). Various food-borne diseases have been associated with poverty, characterized by lack of access to adequate, good quality and nutritious foods. Eradication of extreme poverty and hunger, together with reducing child mortality and improving maternal health, has been a major target of the Millennium Development Goals
(MDG) and sustainable development goals (SDG) formulated by the United Nations (UN, 2015). The rise in population and the potential effect of climate change on and food production pose challenges in making food available to the vulnerable segments of the population. Reducing loss/wastage of food and controlling the incidence of food-borne diseases through improved food safety would play an important role in achieving the target (FAO, 2010). As per WHO's estimate of the global burden of food-borne diseases, children $<5$ years of age experienced $40 \%$ of the food-borne disease burden despite representing only $9 \%$ of the global population (Havelaar et al., 2015). Therefore, reducing the incidence of foodborne diseases in children will be a major step in tackling the problem.

The food chain consisting of procurement of raw materials, primary production processes, manufacturing practices and retailing has been the primary focal point for assessing, monitoring and maintaining food safety to the consumer (Auler et 
al., 2017; Jacxsens et al., 2016). The potential for food safety risks exists throughout the supply chain, and is high in the Indian context due to frequent breakdowns of food safety controls, lack of capacity to handle/monitor/assess food safety issues, lack of efficient food traceability systems, natural disasters, etc.(Dandage et al., 2017). The present article addresses the existing international perspective on handling of food safety risks and standards, the current Indian scenario of food safety risk management and the requirements to strengthen risk management activities in India.

\section{Food Safety Risks and Food-Borne Diseases in India}

Food safety risks include those originating from microbial, fungal, chemical, and physical contamination of food, for e.g. food borne pathogens, naturally occurring toxicants, mycotoxins, heavy metals, pesticide residues, veterinary drug residues, adulterants, and fake foods. Most of the food borne diseases that are recorded in India are of bacterial origin, particularly from Staphylococcus aureus, Salmonella, Bacillus cereus, Vibrio parahaemolyticus and Escherichia coli (Kohli and Garg, 2015). Milk-based foods, rice and meat/chicken preparations have been the main foods with bacterial contamination. Mycotoxicoses outbreaks, such as aflatoxicosis, deoxynivalenol toxicosis, enteroergotism and fumonisin toxicosis due to ingestion of mycotoxinaffected foods have been recorded in India (Krishnamachari et al., 1975; Vasanthi and Bhat, 1998). Various naturally occurring toxicants such as in sea food (e.g. shell fish, clams, and fish containing algal toxins), certain varieties of legumes (e.g. toxic amino acids in Lathyrus sativus) and weeds (e.g. pyrrolizidine alkaloids in Crotolaria species) have been responsible for causing diseases such as lathyrism, and venoocclusive disease. Poisoning of food can occur due to heavy metal toxins, toxic colourants, and pesticides. Several cases of food poisoning caused by adulterants have been described, mostly from toxic colourants in foods and adulteration of edible oils (Tulpule et al., 1982, Vemula et al., 2012).

\section{The Food-borne Disease Burden and Economic Implications for India}

Food-borne diseases (FBD) are an important cause of morbidity and mortality worldwide. The World
Health Organization (WHO) has presented estimates of the burden of FBDs caused by 31 microbial and chemical sources that caused 600 million food borne illnesses and 420,000 deaths (Havelaar et al., 2015). Every year, such illnesses occur in almost 1 in 10 people. It is estimated that the current FBD burden in India is about 100 million cases per year (about 1 in 12 people), caused by various diarrhoeal, infectious, parasitic and chemical agents (Kristkova et al., 2017). In India, FBDs are commonly referred to as 'food poisoning'. As per the data provided by the Integrated Disease Surveillance Programme (ISDP) of the Ministry of Health, Government of India, the number of food poisoning outbreaks and acute diarrhoeal disease outbreaks recorded were 2555 and 4366, respectively, during 2008-2017, while in 2017 alone, a total of 242 and 312 food poisoning and acute diarrhoeal diseases, respectively, were reported. The FBD outbreaks, together with acute diarrhoeal diseases, constitute nearly half of all reported outbreaks of diseases in India (ISDP). The incidence of FBDs is higher in places where food is cooked in bulk, such as canteens, hostels and wedding venues. A comprehensive review on food-borne diseases and food safety in India, covering the entire gamut of the problem including outbreaks, control and preventive measures, laboratory diagnosis, and treatment, was published by the National Centre for Disease Control (CD Alert, 2009). FBDs cost India an estimated \$28 billion (Rs. $1,78,100$ crore) or around $0.5 \%$ of the country's gross domestic product (GDP) every year, as revealed by a study by 'Food for All', a partnership of the World Bank Group and The Netherlands government (Kristkova et al., 2017). The estimate is more than three times the Ministry of Health expenditure budget of Rs. 48,353 crore for 2017-18. It was calculated earlier that, on the basis of per capita income, the economic burden on people affected by an outbreak of Staphylococcus aureus food poisoning in India was found to be higher than in the case of a similar outbreak in the USA. This case study clearly indicated that the economic impact of FDBs is greater in a developing country like India (Sudhakar et al., 1988).

\section{Food Safety Risk Analysis}

Traditional food safety systems are inadequate to cope with the complexities of food safety problems that occur throughout the food chain. While traditional 
hazard-based approaches rely on end-product testing as a basis for risk management action, modern riskbased approaches establish health-based guidance standards for human exposure to chemicals (such as acceptable or tolerable daily intakes) using toxicological data and estimates of human exposure (Barlow et al., 2015).

The international fora are emphasizing use of modern food safety systems with science-based approaches that incorporate the concept of risk analysis (Codex, 2007). Risk analysis provides a means to strengthen the ability of traditional food safety systems to meet current challenges. It provides a framework to effectively manage, assess and communicate risks in cooperation with the diverse stakeholders involved (FAO, 2005; FSANZ, 2013).

\section{Risk Management Pertaining to Food Safety Risks}

Risk management is essential for the protection of public health by controlling food risks as effectively as possible through the selection and implementation of appropriate measures and also by ensuring the availability of safe and wholesome food in the domestic market as well as in international trade (FAO, 2017). The Codex Alimentarius Commission (CAC) established the general principles and concepts related to food safety risk management (FSRM) decision making that could lead to harmonized international standards (Codex, 2007). The desired outcome of risk management process is the development of standards, guidelines and other recommendations for food safety (FAO, 2006).

The risk management framework is built on four interconnected components: (i) preliminary activities wherein food safety issues are identified, a risk profile is developed, the need for risk assessment is determined, and a risk assessment policy is established; (ii) identification and selection of risk management options in the form of guidelines, code of practice, etc.; (iii) implementation of risk management decisions, and (iv) monitoring and review (FAO, 1997). Among these, the most crucial is the implementation of control measures and monitoring, since reduction in food safety risks cannot be achieved unless the control measures developed are implemented effectively (Slorach, 2008). An effective food control implementation system is pivotal to better compliance of food business operators with standards, which in turn will help in controlling the occurrence of food safety hazards (FAO, 2017).

Identification of food safety issues/problems is usually accomplished by domestic/import inspection, food monitoring programmes, environmental monitoring, laboratory, epidemiological, clinical and toxicological studies, human disease surveillance, foodborne disease outbreak investigations, and technological evaluation of novel foods (FSANZ, 2013). The description of a significant food safety problem(s) is essential as it justifies the need for risk analysis and provides a basis for the development of a risk profile. A risk profile is important for prioritizing food safety issues, develop risk assessment policy, determining availability of resources to address the issues, and identifying possible risk management options. It plays an important role in deciding whether risk assessment is required, and also in setting goals and criteria for ranking of hazards (FAO, 2008).

\section{Importance of Establishing Risk Assessment Policy}

Codex describes a risk assessment policy as consisting of documented guidelines for scientific judgement and policy choices to be applied at appropriate decision points during risk assessment (Codex, 2007). Establishing a risk assessment policy as a specific component of risk management is essential for defining the scope and purpose of risk assessment and the manner in which it will be conducted, and to protect the scientific integrity of the risk assessment. The risk assessment policy should also include the parts of the food system, the populations, geographic areas and the time period to be covered, criteria for ranking hazards, procedures for application of safety factors for appropriate level of protection, etc. (Slorach, 2008). Given that the risk assessment process is extremely resource-intensive, it is especially important to prioritize these based on risk ranking (FAO, 1997). The critical part in risk management involves identifying, reviewing, and evaluating various options to manage the risks. The option selected will depend on the desired level of consumer protection (ALOP). The final decision regarding the option to be selected is based on the analysis and comparison of each option against criteria linked to risk management goals, the risk assessment conclusions and effects on key stakeholders. Monitoring and 
evaluation help to assess whether a food control measure used is effective. This is accomplished by generating, gathering and evaluating relevant data sourced from, for example, national surveillance databases for notifiable diseases, disease registries, targeted human surveys (active surveillance) and analytical epidemiological studies, outbreak investigation data for food-borne illness events. It is also important to study the frequency and levels of occurrence of chemical or microbiological contaminants in foods from production to consumption, frequency of occurrence and levels of contaminants in blood, urine or other tissues gathered from representative samples of the population(s) at risk, food consumption survey data and, to the extent possible, for specific subpopulations that may be at risk. Though the required infrastructure for these activities already exists in India a comprehensive approach to food risk management is yet to emerge.

\section{Whole Food Chain Management Approach}

The whole food chain management approach for food safety and quality is one of the most complex of all procedures relating to distribution of food and places a great demands on safety risk management (Auler et al., 2017; FSANZ, 2013). The supply of safe food depends on the extent of coordination among food producers, manufacturers, distributors, retailers and other persons involved in the various processes of food delivery to the consumer. Assessment of the supply chain management and the economics of prioritization and maintaining of logistics to meet consumer demands remains a challenge to the Indian food safety management system. For example, fresh produce and meat are highly susceptible to spoilage and contamination with food-borne pathogens and hence require extra care during production, storage, transport and distribution. On the other hand, cereals and other grains need just efficient storage conditions to prevent mould and insect damage during distribution. Processed food products need a management system for handling traceability and recalls. Thus, a whole-chain approach from farm to table becomes more logical as food safety becomes the responsibility of all stakeholders in the food chain.

\section{Food Safety Risk Management, Risk Categorization and Risk-Based Inspection}

Food safety management system (FSMS) is a series of specifications, procedures, processes, verifications, validations and documentation. It is a holistic system of controls for food safety and includes various prerequisite programmes and monitoring systems (EC, 2016). The pre-requisite programmes or PRPs are Good Hygiene Practices (GHP, e.g. appropriate cleaning and disinfection, personal hygiene), and Good Manufacturing Practices (GMP, e.g. correct dosage of ingredients, appropriate processing temperature). These programmes, together with other procedures of traceability and recall, are also termed as prevention and preparedness systems. The most recognized and successful FSMS monitoring programme is the Hazard Analysis Critical Control Point (HACCP) system that identifies, evaluates and controls hazards significant to food safety and is also termed as Own-check systems (EC, 2016). FSM systems are just picking up in India.

Guidelines are available for assisting regulatory agencies to prioritize their food inspection activities on the basis of risk. These have been popularized in several ASEAN countries (Fardiaz et al., 2011). Risk categorization of food and food establishments provides a framework, by allowing regulatory agencies to prioritize inspections on the basis of risk. It addresses different types of food categories, both imported and domestic, and saves time, cost, and human resources. Food inspection plays an important role in maintaining a safe and nutritious food supply by making sure that the food meets required standard and by assuring safety of food, preventing of adulteration and commercial fraud with respect of sale of food (FAO, 2008). Traditional food inspection systems have been more reactive than preventive. Through using a risk-based approach and prioritizing inspections, regulatory requirements could be matched to food safety outcomes. Many countries in the ASEAN region have incorporated the risk-based approach in their legislation (Fardiaz et al., 2011). In India, risk-based inspection needs to be prioritized and progress beyond the traditional inspection systems. This also calls for harmonization of the present system of diverse inspection systems for separate food sectors and categories into a universal risk-based system through improved/enhanced coordination among the various organizations concerned. In the Indian context, wherein health is in the concurrent list of the Constitution, the role of State governments in implementing the risk-based inspection system is 
critically important.

The FDB risk factors associated with the type of food product or processing varies with each business operator (FAO, 2008). For example operations which have the potential to put vulnerable groups or large numbers of consumers at serious risk due to the nature of food, manner of food preparation or processing, facilities provided, or control system in place will be categorized as high-risk ones. Operations that do not involve the preparation of high-risk readyto-eat foods, but are nevertheless on a large scale such as those involving raw meat, cooked meat/poultry, milk and milk products, egg and egg products, are categorized as medium-risk ones. Operations with low potential to cause harm to consumers, such as primary production of honey, manufacture of cereal products, jams and jelly, oils and fats, and packaging of tea, herbs, spices, nuts, etc. are categorized as low-risk business.

It is important for risk management inspectors to recognize process/product-related sets of risk factors for FDBs and to identify high-risk foods or food preparation processes, so that resources can be allocated appropriately. There are several processproduct related risk factors in the Indian context that need to be identified and brought under the risk-based inspection regime. One such example is the use of raw foods along with cooked foods, such as the garnishing of cooked preparations with raw coriander or onions. Products such as raw chicken are highrisk foods because they naturally carry a high load of pathogenic bacteria and hence any practices that can attract cross contamination achieve highest priority during inspection.

\section{Existing Mechanisms of Food Safety Management in India}

\section{Institutional Set Up : Food Safety and Standards Authority of India}

In India, there was a plethora of fragmented legislation, multiple jurisdictions and weakness in surveillance, monitoring and enforcement, so that neither the safety, nor the quality of food was assured. For this reason it was recommended, as far back as 1981, that a new food safety authority should be established in India (Bhat and Narasing Rao, 1985). However, it could be put in place only almost two decades later, in 2006, when the Food Safety and Standards Authority of India (FSSAI) was created. for laying down science -based quality and safety standards for articles of food and to regulate their manufacture, storage, distribution, sale and import so as to ensure availability of safe and wholesome food for human consumption (FSSAI, 2006). The Food Safety and Standards Act, 2006, was enacted to: (i) consolidate multiple laws in the country relating to food safety, (ii) establish a single-point reference system, and (iii) establish the Food Safety and Standards Authority of India (FSSAI). FSSAI formulates standards for food and regulates their manufacture, storage, and distribution, among others. Due to various factors, the effectiveness of the FSSAI is still far from satisfactory (Bhat 2013). Although the organizational set up consisting of a regulatory and administrative framework, Licensing and Enforcement operations, and food testing laboratories has been established, the Comptroller and Auditor General of India noted several lacunae in its functioning (CAG, 2017).

\section{Capacity Building Activities : Food Safety Risk Management Training}

Food safety risk management training in India should be incorporated into the existing food safety training modules. In the ASEAN countries, including Least Developed Countries like Cambodia and PDR Laos, risk-based food inspections of both domestic and imported foods, are in vogue. In Vietnam, risk -based inspections are incorporated in the food laws. Several training programmes were organized in all the ten ASEAN countries, and guidelines for risk categorization of food and food establishments applicable to ASEAN countries have been published (Fardiaz et al., 2011). The Asian Productivity Organization, Tokyo, has launched several e -learning training programmes on Food Safety Risk Management in food supply chains for various Asian and Pacific Rim countries including India (APO 2017).

The Food Safety and Standards Authority of India (FSSAI) has initiated training programmes in food safety and certification for personnel engaged in food operations. These include 16 courses at three levels, namely, basic, advanced and special, of 4-12 hours duration for the training of food business operators in catering, manufacturing, storage, retail and transport, as well as for those in product-specific 
areas including milk, meat and poultry. These programmes are imparted in online or offline modes with specific focus on food safety management system practices such as Good Hygiene Practices (GHP) and Good Manufacturing Practices (GMP) (Kumar and Inamdar 2017). However, awareness and training programmes on food safety risk management in India need to be further evolved and strengthened for effective implementation of food safety risk management and a risk-based food control system.

\section{Way Forward}

It is necessary to urgently evolve a risk management framework taking a whole-food-chain approach for addressing various food safety hazards/issues by taking the following steps: i) identify and prioritize food safety issues, ii) carry out risk-based inspection of various food operations and businesses and product/process related food risk factors, iii) evolve a robust risk assessment policy, iv) evolve criteria for selecting options and implementation of risk management decisions, and v) put in place mechanisms for monitoring and review. An assessment of the impact of implementation and enforcement of the Food safety Act should include both the protection of consumer health and the economic impact. Transparent and clearly defined processes are required in incorporating risk-based approaches to food-related activities

\section{References}

APO (2017) Asian Productivity Organization e -learning Course on Food Safety Risk

Management in Food Supply Chains, 2017 http://www.apotokyo.org/annual_programs/pdf/1499239793/PN\%20eLearning\%2017-AG-28 GE-LN-B\%20(Food\%20Safety\% 20Risk\%20Managament\%20in\%20Food\%20Supply\% 20Chains). pdf(accessed on 5June 2018)

Auler D P, Teixeira R and Nardi V (2017) Food safety as a field in supply chain management studies: a systematic literature review Int Food Agribusiness Manag Rev 20 99-112

Barlow S M, Boobis A R, Bridges J, Cockburn A, Dekant W, Hepburn P, Houben G F, K•onig J, Nauta M J, Schuermans J and Banati D (2015) The role of hazard- and risk-based approaches in ensuring food safety Trends Food Sci Technol 46 176-188

Bhat R V (2013) Achieving food safety from farm to table: Global requirements and the Indian scenario NFI Bulletin 34: 1-8 wherever practicable. It should be ensured that all aspects of internationally recognized risk analysis practice, i.e, risk assessment, risk management and risk communication, are combined with monitoring and reviewed logically so as to maximise the benefits. Robust science should be a key input to all components of the Risk Management Framework. The evolution and refinement of the food safety risk management policy in India should be driven by economists, food scientists, and public health analysts. Several public policy questions persist, illustrating the need to balance food safety issues or potential public health hazards with other competing issues. For instance: How do we determine acceptable levels of safety in concert with the other goals of society and what should these levels be? How do we establish food safety and public health priorities? What should be the relative roles of governments, the private sector, and individuals in assuring food safety, health, environmental quality and other desired goals of the food system? And what is the best combination of policy instruments available to attain both the desired level of food safety and other goals? The FSSAI needs to address these issues, and make the implementation of the food safety programmes, including risk management aspects, effective at the Central, State and local health authority levels.

Bhat R V and Narasinga Rao B S (1985) National strategy for food quality control, National Institute of Nutrition Hyderabad pp 1-207

CAG (2017) Report of the Comptroller and Auditor General of India on Performance Audit of Implementation of Food Safety and Standards Act, 2006 Union Government (Civil) Ministry of Health and Family Welfare Report No. 37 of 2017 (Performance Audit) pp 85

CD Alert (2009) Food borne diseases and food safety in India Monthly Newsletter of National Centre for Disease Control, Directorate General of Health Services, Government of India 13 1-16

CODEX (2007) Working principles for risk analysis for food safety for application by governments. CAC/GL 62-2007. Codex Alimentarius Commission of the United Nations

Dandage K, Badia-Melis R and Ruiz-García L (2017) Indian perspective in food traceability: A review Food control 71 $217-227$ 
Diabat A, Govindan K and Panicker V V (2012) Supply chain risk management and its mitigation in a food industry Int $J$ Prod Res 50 3039-3050

EC (2016) Information from European Union institutions, bodies, offices and agencies European Commission Official Journal of the European Union C 278/1-32 https://eur-lex.europa. eu/legal-content/EN/TXT/PDF/?uri=OJ:C:2016:278: FULL\& from=EN (accessed on 12 April 2018)

FAO (1997) Risk management and food safety Report of a Joint FAO/WHO Consultation Rome, Italy, 27 to 31 January 1997 Food and Agriculture Organization of the United Nations, Rome

FAO (2005) Food Safety Risk Analysis Part I An Overview and Framework Manual Provisional Edition.Food and Agriculture Organization of the United Nations, Rome pp $1-76$

FAO (2006) Food safety risk analysis- A guide for national food safety authorities FAO Food and Nutrition Paper 89 Food and Agriculture Organization of the United Nations, Rome pp 1-95

FAO (2008) Risk-based food inspection manual FAO Food and Nutrition Paper 87 Food and Agriculture Organization of the United Nations, Rome pp 1-85

FAO (2010) Food comes first FAO and the eight Millennium Development Goals Food and Agriculture Organization of the United Nations, Rome

FAO (2017) Trade and food standards Food and Agriculture Organization and World Trade Organization pp 1-57

Fardiaz D, Bhat R and Sareen S (2011) Guidelines for risk categorization off food and food establishments applicable to ASEAN countries Food and Agriculture Organization of the United Nations Regional Office for Asia and the Pacific, Bangkok pp 1-32

FSANZ (2013) Risk Analysis in Food Regulation Food Standards Australia New Zealand pp 3-112 http://www.food standards.gov.au/publications/riskanalysisfood regulation/ Pages/default.aspx (accessed on 8 May 2018)

FSSAI (2006) Food Safety and Standards Act (2006). Food Safety and Standards Authority of India, New Delhi

Havelaar A H, Kirk M D, Torgerson P R, Gibb H J, Hald T, Lake R J, Praet N, Bellinger D C, de Silva N R, Gargouri N, Speybroeck N, Cawthorne A, Mathers C, Stein C, Angulo F J and Devleesschauwer B (2015) World Health Organization Global Estimates and Regional Comparisons of the Burden of Foodborne Disease in 2010 PLoS Med 12 e1001923 doi:10.1371/journal.pmed.1001923

Integrated Disease Surveillance Programme (IDSP) National Centre for Disease Control Directorate General of Health Services Ministry of Health and Family Welfare Government of India Available at http://www.idsp.nic.in (accessed on 3 June 2018)

Jacxsens L, Uyttendaele M, Luning P and Allende A (2016) Food safety management and risk assessment in the fresh produce supply chain International Conference on Food Science and Engineering IOP Conf. Series: Materials Science and Engineering 193 doi: 10.1088/1757-899X/193/1/012020

Kohli C and Garg S (2015) Food Safety in India: An Unfinished Agenda MAMC J Med Sci 1 131-5

Krishnamachari KA, Nagarajan V, Bhat R V and Tilak T B (1975) Hepatitis due to aflatoxicosis - an outbreak in Western India Lancet 305 1061-3

Kristkova Z S, Grace D and Kuiper K (2017) The economics of food safety in India - a rapid assessment Amsterdam, Netherlands: Wageningen University \& Research Available at https://cgspace.cgiar.org/bitstream/handle/10568/89203/ Economics\%20food\%20safety\%20India.pdf(accessed on 31 May 2018)

Kumar A K and Inamdar A A (2017) Skill development initiative - Food industry perspective Indian Food Industry 36 3646

Slorach S A (2008) Food safety risk management in New ZealandA review of the New Zealand Food Safety Authority's risk management framework and its application Ministry for Primary Industries www.mpi.govt.nz/ (accessed on 17 April 2018)

Sudhakar P, Nageswara Rao R, Bhat R V and Gupta C P (1988) The economic impact of a food borne disease outbreak due to Staphylococcus aureus J Food Prot 51 898-900

Tulpule P G, Nagarajan V and Bhat R V (1982) Environmental Contaminants of Food in India. Department of Environment, Government of India, New Delhi, pp 84

Vemula S R, Kumar N R, Polasa K (2012) Foodborne diseases in India - a review Brit Food J114 661-680

UN (2015) The Millennium Development Goals Report. United Nations http://www.un.org/millenniumgoals/2015_MDG_ Report/pdf/MDG\%202015\% 20rev\%20(July\%201).pdf (accessed on 25 May 2018)

Vasanthi S and Bhat R V (1998) Mycotoxins in food-Occurrence, health and economic significance and food control measures Indian J Med Res 108 212-224

WHO Burden of foodborne diseases in South East Asia WHO Regional Office for South East Asia 2016http://www.searo. who.int/about/administration_structure/cds/burden-offoodborne-sear.pdf (accessed on: 23 April 2018). 